\title{
Hypothesis
}

\section{Lay understanding of genetics: a test of a hypothesis}

\author{
Martin Richards, Maggie Ponder
}

\begin{abstract}
There have been growing calls for more education in genetics for the public and in schools. However, studies of the public, school children, and those who have received genetic counselling show that understanding of scientific genetics is very limited. A hypothesis to explain this limited understanding is proposed and tested. It is argued that there is a widespread lay knowledge of inheritance which conflicts in a number of aspects with scientific explanations and which impedes the assimilation of the latter. It is suggested that this lay knowledge is derived from concepts of the social relationships of kinship. Concepts of kinship ties are sustained by everyday social activities and relationships which may make them resistant to change.

A prediction which follows from the hypothesis that the lay understanding of genetics is derived from concepts of family and kinship relationships is that closeness in genetic terms will be determined by the closeness of the family ties of social relationship and social obligation. While the proportion of genes shared with parents, children, and sibs is, on average, the same, kin relationships and obligations are much stronger between parents and children than between sibs. The hypothesis was tested in a questionnaire study of two samples of adult women $(n=64$ and $n=$ 113) and one of social science students $(n=$ 73). In all three groups a higher proportion of subjects gave the correct response for the proportion of shared genes with a father and child than with a sister, uncle, or grandmother. In the cases of sisters and uncle (and grandmother), there was a consistent tendency to underestimate the degree of genetic connection as predicted by the hypothesis. Answers to other questions are consistent with the hypothesis.

The fundamental implications of the hypothesis for genetic education in the clinic and classroom are outlined. (F Med Genet 1996;33:1032-1036)
\end{abstract}

Key words: genetic education; genetic counselling; kinship.

In recent years there have been growing calls for more public education in genetics. ${ }^{1-3}$ This is justified on the grounds that a more general "genetic literacy" is a precondition for appropriate use of predictive tests and other new genetic techniques and would lead to more public involvement in debates on the ethics and deployment of new technologies. In Britain, responses to these calls include a growing representation of genetics in the National Curriculum for schools. However, despite such moves, and indeed the efforts to popularise mendelian genetics throughout the century, public understanding of scientific genetics is very limited. This has been shown in studies of school children and young people, ${ }^{4-8}$ those who have attended genetic counselling, ${ }^{9-12}$ and the public at large. ${ }^{81314}$

This paper describes a hypothesis which might account for the poor public understanding of genetics and a test of this. It is argued that the mendelian explanation conflicts in a number of ways with a lay knowledge of inheritance which is general in society. The conflicts between the mendelian explanation and pre-existing lay knowledge makes the assimilation of the scientific account difficult. A similar point has been argued in the context of the classroom and it has been suggested that the presence of previous ideas which students bring to a class may interfere with their acquisition of scientifically acceptable concepts. $^{715}$

We further suggest that lay knowledge of inheritance is grounded in concepts of kinship that are themselves sustained by everyday social activities and relationships, which may make them particularly resistant to change.

Knowledge about the inheritance of family characteristics is part of family culture in western societies. Such knowledge includes the inheritance of physical characteristics, of aspects of behaviour, character, personality, mannerisms, and personal habits, as well as health and proneness to illness. ${ }^{16-19}$ For example, much family discussion of a new baby or of family photographs or portraits centres around questions of resemblances and who "takes after" whom. Some members of families which carry inherited disorders are only too well aware without the intervention of genetic counselling that the disorder "runs in the family". Research with families with a family history of ovarian and breast cancer indicates that some describe 
a "proneness" to the cancer which is passed from mothers to daughters. ${ }^{2021}$

Lay accounts of inheritance diverge from mendelian explanations over the nature of a hereditary substance and in the segregation of phenotypic characters. In lay accounts sexual intercourse and conception are identified as the key processes in which maternal and paternal contributions are united, but exactly what is transmitted between generations usually cannot be specified. Some of our interviewees mention "genes", "DNA", or "chromosomes" being passed on to children but most lay descriptions do not specify how these may be related to inherited (phenotypic) characters. Often these terms seem to be used to denote a general concept of inheritance rather than referring to a physical substance that is transferred between generations. Lay descriptions generally lack concepts of genotype and phenotype and the idea of a developmental process that links these. This, of course, makes explanation of gene expression and penetrance very difficult in the clinic.

Often phenotypic characters are seen as being joined together and are passed between generations in collections, that is, frequently there is no concept of the segregation of mendelian characters. Those family members who resemble each other are often seen to share "a proneness" for the disorder that runs in the family. ${ }^{22}$ A respondent may say that they "take after" a family member who had a familial cancer and so they are likely to get it, or the converse. Ideas such as this (or skipping a generation) are often used to account for the intermittent appearance of mendelian diseases in families.

The general features of lay explanations seem to be derived from ideas of social connections between kin. ${ }^{18}$ The link we are postulating between ideas of kinship and inherited connections is consistent with what is known of the development of these concepts in children. Four to five year old children have been shown, using animal examples, to believe that those in the kinship relationship of parent and child are more likely to share physical and behavioural characteristics than similar looking animals which are unrelated, but are friends. ${ }^{19}$ In a similar study, but using human examples, children of this age expected offspring to resemble parents in terms of physical characteristics but they drew no distinction between adoptive and biological parents. Only after the age of $7 \mathrm{did}$ a significant (56\%) number of children draw this distinction suggesting that only by this age had children begun to understand that the resemblances were transmitted by reproduction. ${ }^{23}$

The English (and North American and other societies derived from western Europe) kinship system is bilateral. That is to say that a more or less equal social role is given to the two sides of the family. ${ }^{24-26}$ This system of bilateral kinship parallels the idea common to most lay accounts that children inherit a more or less equal set of characteristics from each parent which mix to form the child.
Our kinship system is also one that emphasises descent. ${ }^{27}$ Goods and property are usually passed down from parents to children. Social and legal obligations follow the same vertical pattern linking parents and children much more strongly than lateral links between, say, brothers and sisters. Grandparents are part of the same descent system and, for instance, this is articulated in the legal system which acknowledges their connection with their grandchildren in ways that are not true between, for instance, uncles and aunts and nephews and nieces. ${ }^{28}$

A prediction follows from the idea that family relationships and kin form the basis from which the lay understanding of inheritance is derived: the perceived closeness in inherited (genetic) terms will be determined by the closeness of the family ties of social and emotional relationship and of obligation, duty, and responsibility. This can be tested by examining situations where there is a divergence between the genetic connection on one hand and the strength of the kin tie on the other. The comparison of the perceived genetic connections of parents and children on one hand and sibs on the other provides a test of the hypothesis. If lay knowledge of inheritance is derived from kinship understanding, we would predict that respondents would see genetic connection closer in the former case than the latter. The studies reported below set out to test this prediction

\section{Methods}

Questionnaires designed to assess public knowledge of genetics and attitudes to new genetic technologies were sent to two samples of women and distributed to a mixed student group in a class. Here we will only report data concerned with ideas of genetic connectedness. The respondents $(n=64)$ were members of Women's Institutes (a voluntary organisation concerned with adult education) throughout the UK who had volunteered to attend a three day residential course, "Genetics Now", on new genetic technologies. Each woman was sent a questionnaire before the conference. In addition, she was asked to pass on two further identical questionnaires to two fellow members of her Women's Institute branch of similar age with similar numbers of children, who were not going to the conference. This provided a further 113 respondents ("friends"). The response rates were $100 \%$ for the conference attenders and $88 \%$ for their friends. A slightly modified version of the questionnaire was also completed by a class of first year university social science students $(n=73)$. Their response rate was $100 \%$. The average ages for the three groups were 56 years for the conference attenders, 54 years for the friends, and 19 years for the students. Sixty eight percent of the students were female.

The questionnaires included the questions "what proportion of genes does someone, on average, share with their father, sister, child, uncle, grandmother?" The possible response options were none, $5 \%, 15 \%, 25 \%, 50 \%, 75 \%$, 
Table 1 What proportion of genes does someone, on average, share with their father, sister, child, uncle, and grandmother, as percentages. Correct answers in bold

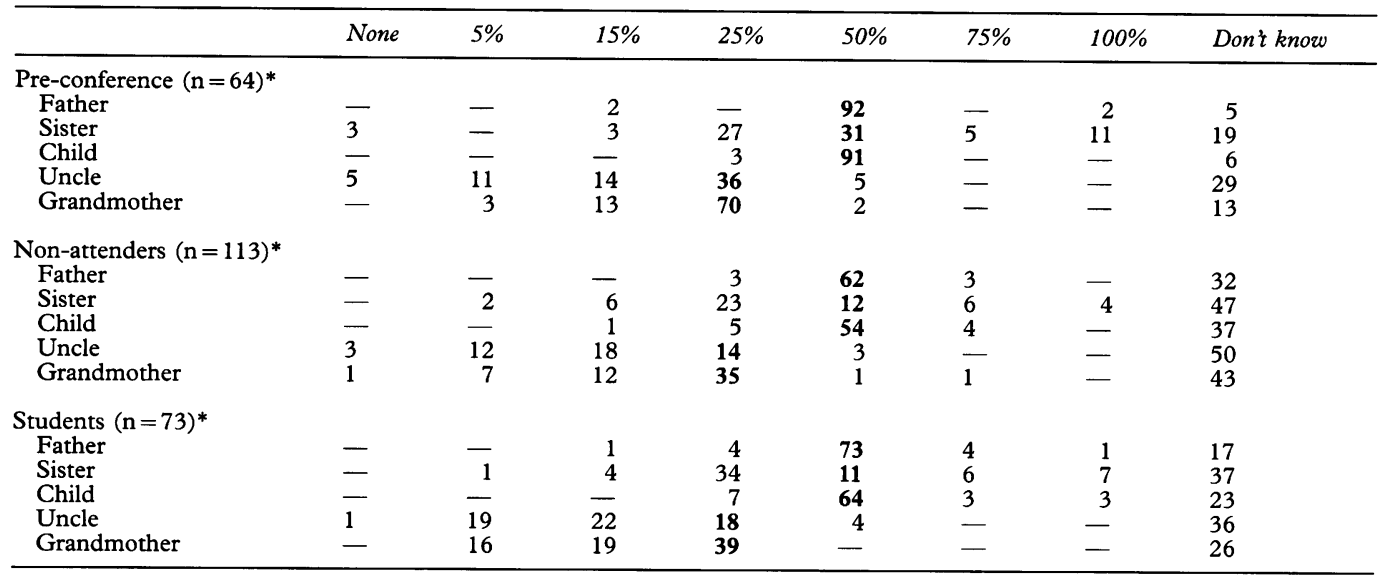

* There are some slight variations in the numbers for some questions because of missing data.

$100 \%$, or don't know. These particular kin terms were selected to include both "descent" (father, child, and grandmother) and "lateral" kin (sister) to test our prediction and provide a balance of terms relating to each gender. Grandmother was included as an example of kin in the line of descent but with whom social connections are less strong than with parents and children, and uncle as an example of lateral kin in the previous generation.

\section{Results}

Those going to the conference, their friends, and the students all gave a similar pattern of answers to the question about the proportion of genes shared with the five different relatives. In each group a majority selected the correct response for father and child, but this was only true for a minority of each group with sister and uncle (table 1). For these latter two questions the majority underestimated the degree of shared genes while the numbers saying they did not know increased sharply.

For all three groups significantly more respondents gave the correct mendelian answers for father than for sister. The friends and students gave significantly more correct responses for father than child but here the numbers are very small. There were no significant differences in any of the three groups between the number of correct answers for uncle and sister.

For all three groups there was a significant tendency to underestimate the number of genes shared with sister, uncle, and to a lesser extent with grandmother, but not father or child.

There were significantly more don't know responses for the questions about sisters, uncles, and grandmothers than for fathers. However, perhaps surprisingly, there were significantly more friends and students who answered don't know to the questions about child than father, but numbers for this comparison are very small.

There were significant correlations between the way people answered for the five different relationships (Spearman correlation coefficients all reached significance of $\mathrm{p}<0.05)$.
This indicates that people were largely consistent in their responses.

Two other questions in our questionnaire are relevant to our hypothesis. Respondents were asked to state whether or not a series of statements were true, false, or that they did not know. A majority of respondents indicated correctly that the statement that "a daughter inherits more of her genes from her mother than her father" (91, 73, and $70 \%$ for conference attenders, friends, and students respectively) was false. Believing this statement to be false is consistent with a bilateral kinship system which does not have different terms for kin on the two sides of the family. However, responses to another statement, "human eggs and sperm contain half the amount of genetic material found in other cells in the body", indicate a widespread view which is not consistent with the process of mendelian inheritance. While $59 \%$ of the conference attenders thought this statement was true, this was so for only $47 \%$ of the students and $28 \%$ of friends.

Those going to the conference, compared with the friends, tended to have significantly more post 16 education and those in employment were more likely than their friends to have a job with a medical or scientific connection. Significantly more of the attenders stated that a family member had an inherited disorder $(53 \% v 27 \%)$, that they had received genetic counselling ( $15 \% v 3 \%)$, and had had experience of inherited disorders outside the family $(58 \% v 28 \%)$. That they had volunteered to go to the conference indicates an interest in genetics. These factors seem likely to account for the higher proportion of mendelian responses from them as compared with the Women's Institute members who were not going to the conference. ${ }^{29}$ Of the 73 students, nine had taken biology at A level. This (small) subgroup were more likely to have chosen the correct mendelian responses.

\section{Discussion}

The pattern of responses across the groups was remarkably consistent and clearly follows the 
prediction derived from our hypothesis. The proportion of genes thought to be shared with fathers and children was more often correct than for other kin. Not only was the proportion of each group making the correct response much lower for the other three relatives, but there was a consistent tendency to underestimate the proportion of shared genes, especially for sisters and uncles. The higher proportion of respondents who indicated that they did not know the proportion for sister, uncle, and grandmother, compared with father and child, suggests more uncertainty for the connection with the more distant relatives. This would be paralleled by more uncertainty of kin obligations and duties in respect to these relatives. ${ }^{28}$ This was less marked for grandmother, perhaps reflecting the position of this relative in the line of descent.

The greater proportion of those going to the conference selecting the correct responses suggests, in view of their longer education, higher proportion of relevant employment, and interest and involvement in genetics, that this is the result of more scientific knowledge of genetics. Results for the student sample are consistent with this interpretation. In other words, for these people, a scientific perspective on these matters has come to predominate over, or replace, lay knowledge.

It might be suggested that the pattern of results could be explained by the fact that, while the proportion of genes transmitted from each parent to a child is fixed, there is individual variability in the case of the lateral relationships. However, while this consideration, assuming it is understood by the respondents, could lead to more uncertainty about the relatives other than parents and children, it does not explain why the proportion shared is systematically underestimated for the other relatives. However, such uncertainty might contribute to a higher proportion of respondents stating they did not know the answer in the case of other kin. More simply, it might be suggested that people have more difficulty in calculating ratios for more distant kin. ${ }^{30}$ However, this would not explain the systematic pattern of underestimation for the more distant kin. There seems no reason to expect errors in calculation to follow this pattern. However, this factor might help to explain the higher proportion saying they did not know the answer for more distant kin.

One further point needs to be made about the perceived connection between parents and children. In all three groups, a higher percentage of respondents gave the correct response for the proportion of genes shared with a father and a child than for other relatives. Very few respondents gave incorrect responses for these two cases. There was also a significant number of respondents who did not know the answer to the question about father and, particularly, child. This, together with the answers to our question about mothers and daughters, suggests that while many adults recognise the equal contribution of the two parents to inheritance, a significant minority may not. This is consistent with the evidence that, for some people, the belief is that the proportion of the contribution of each parent may depend on such individual features as the "strength" of the particular characteristic or whether or not it is "dominant", rather than there being an overall rule describing the situation. Many school children and a few adults believe that paternal influences are more important for sons, and maternal influences for daughters. ${ }^{46}$ In our study, about $12 \%$ of friends and students thought the statement that "a daughter inherits more of her genes from her mother than her father" was true; the figure was $5 \%$ for the conference participants. ${ }^{26}$ These considerations will be relevant when counselling families with sex linked disorders or for conditions which largely affect one sex, such as breast cancer. ${ }^{21}$

The hypothesis described in this paper could be further tested by examination of these questions in cultures with differing patterns of kinship connectedness. It is planned to do this with a number of ethnic communities from the Indian subcontinent. These are cultures which tend to emphasise lateral kin connections much more strongly than is the case for English kinship and draw distinctions between roles of relatives on the two sides of the family. These considerations make these cultures a good test for the hypothesis. It might be added that if the hypothesis is correct one might expect to encounter particular problems in genetic counselling with members of these ethnic minorities. ${ }^{31}$

The hypothesis presented here, if correct, has considerable implications for genetic education in the clinic, classroom, and more generally. It lends support to the view that any explanation should begin from an understanding of the pre-existing knowledge that a person may bring to a learning situation and focus on the conflicts between this and the mendelian explanation. ${ }^{1821}$ In short, education should proceed, as has been long advocated by some in science education, ${ }^{32}$ from the "bottom up" rather than the traditional "top down" approach which begins with the scientific position and attempts to provide a simplified account of this. Top down accounts which ignore the previous knowledge of those who come to genetic clinics or of school pupils ${ }^{73}$ are unlikely to be successful in achieving widespread scientific understanding. We are currently engaged in designing empirical tests of an evidence based bottom up approach to genetic education in schools and clinics. ${ }^{18}$

We are grateful to all our respondents for the time and trouble they took in completing our questionnaires. We would like to thank Sally Roberts, Kostas Kafetsios, and Jill Brown for technical assistance and Jenny Lewis, Michael Reiss, Colin WoodRobinson, and members of the Centre for Family Research for
comments on earlier drafts of this paper. This research has been comments on earlier drafts of this paper. This research has been
supported by grants to M P M Richards from the Medical supported by grants to M P M Richards from
Research Council and the Nuffield Foundation.

1 Griffiths AJF. What does the public really need to know about genetics? Am f Hum Genet 1993;52:230-2.

Turney J. Signs of life - taking genetic literacy seriously. The Genetic Engineer and Biotechnologist 1995;15:181-6.

3 House of Commons Science and Technology Committe Third Report. Human genetics: the science and its consequences. Vol 1. London: HMSO, 1995.

4 Kargbo B, Hobbs ED, Erickson GL. Children's beliefs about inherited characteristics. $\mathcal{F}$ Biol Educ 1980;14:137-46.

5 Longden B. Genetics - are there inherent learning difficulties? F Biol Educ 1982;16:135-40. 
6 Clough EE, Wood-Robinson C. Children's understanding of inheritance. F Biol Educ 1985;19:304-10.

7 Wood-Robinson C. Young people's ideas about inheritance and evolution. Stud Sci Educ 1994;24:29-47.

8 Ponder M, Lee J, Green J, Richards M. Family history and perceived vulnerability to some common diseases: a study of young people and their parents. $\mathcal{F}$ Med Genet 1996;33: 485-92.

9 Kessler S. Psychological aspects of genetic counselling. VI. A critical review of the literature dealing with educatio
and reproduction. Am $\mathcal{F}$ Med Genet 1989;34:340-53.

10 Michie S, Marteau T. Genetic counselling: some issues of theory and practice. In: Marteau T, Richards MPM, eds. The troubled helix: social and psychological implications of the new human genetics. Cambridge: Cambridge University Press, 1996.

11 Shiloh S. Decision-making in the context of genetic risk In: Marteau T, Richards MPM, eds. The troubled helix: social and psychological implications of the new human genetics. Cambridge: Cambridge University Press, 1996.

12 Snowdon C, Green J. Recall of risk: what does this mean for carriers of recessive disorders? Unpublished paper, for carriers of recessive disorders? Unpublished paper,

13 Durant J, Hansen A, Bower M. Public and press discourse on the human genome project in Britain. In: Marteau
T, Richards MPM, eds. The troubled helix: social and T, Richards MPM, eds. The troubled helix: social and psychological implications of the new human
bridge: Cambridge University Press, 1996.

14 Nelkin $\mathrm{D}$, Lindee MS. The DNA mystique. The gene as a cultural icon. New York: Freeman.

15 Simpson M, Arnold B. The inappropriate use of subsumers in biological learning. Eur f Sci Educ 1982;4:173-84.

16 Davison C, Frankel S, Smith GD. Inheriting heart trouble: the relevance of common-sense ideas to preventative measures. Health Educ Res 1989;4:329-40.

17 Richards MPM. Families, kinship and genetics. In: Marteau T, Richards MPM, eds. The troubled helix: social and psychological implications of the new human genetics. Campsychological implications of the new human

18 Richards MPM. Lay and professional knowledge of genetics and inheritance. Public Understanding of Science 1996;5: 217-30.

19 Springer K. Children's beliefs about the biological implications of kinship. Child Dev 1992;60:637-48.

20 Green J, Murton F, Statham H. Psychosocial issues raised by a familial ovarian cancer register. $\mathcal{f}$ Med Genet 1993 ; 30:101-5.

21 Richards MPM, Hallowell N, Green JM, Murton F, Statham $\mathrm{H}$. Counselling families with hereditary breast and ovarian cancer: a psychosocial perspective. $\mathcal{f}$ Genet Couns 1995;4: 219-33.

22 Davison C. Predictive genetics: the cultural implications of supplying probable futures. In: Marteau $\mathrm{T}$, Richards MPM, eds. The troubled helix: social and psychological im plications of the new human genetics. Cambridge: Cambridge University $P$

23 Solomon GEA, Johnson SC, Zaitchik D, Carey S. Like father, like son: young children's understanding of how and why offspring resemble their parents. Child Dev 1996; 67:151-71.

24 Schneider DM. American kinship: a cultural account. Englewood Cliffs, NJ: Prentice Hall, 1968.

25 Rapp R. Heredity or: revising the facts of life. In: Yanagisako $S$, Delaney $C$, eds. Naturalizing power. Essays in feminist cultural analysis. New York: Routledge, 1992.

26 Strathern M. After nature: English kinship in the late twentieth century. Cambridge: Cambridge University Press, 1992.

27 Craig D. Immortality through kinship: the vertical transmission of substance and symbolic estate. Am Anthropol 1979;81:94-5.

28 Finch J. Family obligations and social change. Cambridge: 1989.

29 Richards MPM, Ponder M. A report of the "Genetics Now" conference. An unpublished report for the Medical Research Council. Centre for Family Research, University of Cambridge, 1996.

30 Hallowell N, Richards MPM. Understanding life's lottery: an evaluation of studies of genetic risk awareness. $f$ Healt Psychol (in press)

31 Ahmed WIU. "Race" and health in contemporary Britain. Buckingham: Open University Press.

32 Layton D, Jenkins E, Maegill S, Davey A. Inarticulate science? Perspectives on the public understanding of science and some Perspectives on the public understanding of science and some
implications for science education. Driffield, Yorks: Studies in Education Ltd, 1993.

33 Wood-Robinson C. Children's biological ideas - what do our students know about ecology, inheritance and evol-
ution. In: Glynn S, Duit R, eds. Learning science in schools. ution. In: Glynn S, Duit R, eds. Learning science in schools. Association for the Advancement of Science, 1994. 